\title{
PREFERENSI MUSIK DAN KECERDASAN EMOSI MAHASISWA PROFESI NERS UNIVERSITAS KLABAT
}

\author{
Grace F. Kaparang, Mega Gayo
}

Profesi Ners Universitas Klabat, Jl. Arnold Mononutu, Airmadidi, Minahasa Utara, Sulawesi Utara, 95371

email: gfk379@gmail.com

\begin{abstract}
Emotional intelligence is crucial in life; thus, proper stimulations, including music, were necessary. The study aimed to identify the relationship between music preference and emotional intelligence and also to find if there is any significant difference in emotional intelligence among music preference groups. Descriptive correlational method with cross-sectional approach and purposive sampling technique were employed. Most of the students prefer unpretentious music genres and having "moderate" emotional intelligence $(M=121.85$, SD=11.3). No significant difference in emotional intelligence between music preference groups from Kruskal-Wallis analysis; however, Spearman's analysis shown that "sophisticated" music genre was positively weak correlated with emotional intelligence $(p=.028<.05 ; r=.218)$. Furthermore, the music type of Gospel, New Age, Pop, Religious and Soundtracks type of music were positively weak correlated with emotional intelligence, while Punk was negatively weak correlated. It is recommended that profesi ners students be wise in music selection since music may have a significant impact on emotional intelligence, and for further studies should ensure that the participants are familiar with the STOMP that they may understand the genre. Furthermore, future studies also may use direct observatory analysis for emotional intelligence by giving situational experiment to the participant rather than just using a selfrated questionnaire.
\end{abstract}

Keywords: emotional, intelligence, music, student, nurse

\begin{abstract}
Abstrak
Kecerdasan emosi memiliki peran yang sangat penting untuk kehidupan karena itu perlu adanya stimulus yang tepat, salah satunya musik. Tujuan penelitian ini adalah untuk mengidentifikasi perbedaan kecerdasan emosi berdasarkan preferensi musik dan juga mengidentifikasi hubungan preferensi musik dengan kecerdasan emosional. Metode yang digunakan dalam penelitian ini adalah observasional analitik deskriptif korelatif dengan pendekatan cross sectional dengan teknik purposive sampling. Hasil penelitian ini menunjukkan paling banyak mahasiswa menyukai musik dengan genre unpretentious dan memiliki kecerdasan emosi "sedang" $(M=121.85, S D=11.3)$. Ditemukan juga bahwa tidak ada perbedaan dalam kecerdasan emosional berdasarkan preferensi musik berdasarkan uji Kruskal-Wallis, namun dari uji Spearman menunjukkan genre "sophisticated" memiliki hubungan positif yang signifikan dengan kecerdasan emosi, namun keeratannya lemah ( $p=.028<.05 ; r=.218)$. Kemudian, jenis musik Gospel, New Age, Pop, Religious dan Soundtracks memiliki hubungan positif dengan kecerdasan emosi, sedangkan musik Punk memiliki hubungan yang negatif, walaupun keeratan hubungannya lemah. Rekomendasi bagi mahasiswa profesi ners agar bijaksana memilih jenis aliran musik yang tepat guna meningkatkan kecerdasan emosional dan bagi peneliti selanjutnya yang ingin mengadopsi dan menggunakan Tes Preferensi Musik (STOMP) harus memastikan bahwa mereka mendengarkan setidaknya satu dari lagu-lagu tersebut, agar peserta tahu jenis musik yang dimaksud. Penelitian selanjutnya juga dapat melakukan pengukuran observasi perilaku langsung dengan memberikan ujian situasional untuk menguji kecerdasan emosi kepada partisipan gantinya menggunakan kuesioner "self-rated".
\end{abstract}

Kata kunci : kecerdasan emosional, musik, mahasiswa profesi ners, preferensi

\section{Pendahuluan}

Akhir-akhir ini muncul kekhawatiran yang besar dari para orangtua terhadap suatu data yang berasal dari sebuah survei besar-besaran terhadap para orangtua dan guru yang memperlihatkan adanya kecenderungan yang sama di seluruh dunia, yaitu generasi sekarang lebih banyak mengalami kesulitan emosional daripada generasi sebelumnya. Mereka lebih kesepian, pemurung, lebih berangasan, kurang menghargai sopan 
santun, lebih gugup, mudah cemas, lebih impulsif dan agresif (Goleman, 2000). Kecerdasan emosional adalah kemampuan seseorang atau peserta didik untuk mengenali dan mengelola emosi diri, memotivasi diri sendiri, mengenali emosi orang lain dan kemampuan untuk membina hubungan (bekerjasama) dengan orang lain (Sandi, 2018).

Kecerdasan emosi memiliki peran yang sangat penting untuk kehidupan karena itu perlu adanya stimulus yang tepat, salah satunya dengan menggunakan musik, karena musik adalah unsur yang paling dekat dengan kehidupan manusia (Fitroh \& Khasanah, 2016). Musik adalah suatu hal yang bersifat universal dan tidak mengenal golongan masyarakat. Siapapun dapat mengapresiasi musik walaupun ia tidak terpelajar dalam bidang musik. Musik digunakan banyak orang sebagai media untuk mengekspresikan diri (dapat berupa ideide atau nilai-nilai yang diyakininya), juga sebagai hiburan karena didalamnya terkandung lirik-lirik yang sesuai dengan emosi yang sedang dirasakan seseorang, seperti senang, sedih, marah, gelisah, takut, cemburu, semangat dan sebagainya (Hamzah, 2010).

Musik memberikan dampak nyata pada perkembangan emosi dan spiritual manusia (Kompasiana, 2018). Banyak sekali dampak yang terjadi bila kecerdasan emosional tidak dikembangkan, karena jika hanya mengedepankan kecerdasan rasional tanpa menyeimbangkannya dengan kecerdasan emosional dapat menimbulkan perilaku brutal yang berujung pada tindakan kriminal (Iqlima, 2019).

Berdasarkan pengalaman peneliti selama kuliah S1 ditemukan rata-rata mahasiswa memiliki kematangan emosional serta pengelolaan stress yang kurang baik dan menyebabkan banyaknya mahasiswa tertekan hingga terdapat mahasiswa tidak menyelesaikan studinya. Pada perkuliahan profesi ners ini, mahasiswa terpapar dengan berbagai tekanan dari masalah ekonomi, beban studi hingga pergaulan dalam lingkungan perkuliahan dan banyak faktor lainnya, maka berdasarkan uraian diatas peneliti tertarik untuk meneliti tentang preferensi musik dan kecerdasan emosi pada mahasiswa profesi ners Universitas Klabat.

\section{Metodologi}

Metode yang digunakan yaitu metode observasional analitik deskriptif korelatif dengan pendekatan cross sectional. Selanjutnya, teknik sampling yang digunakan pada penelitian ini adalah purposive sampling yaitu salah satu teknik non random sampling dimana peneliti menentukan pengambilan sampel dengan cara menetapkan sesuai ciri-ciri khusus yang sesuai dengan tujuan penelitian sehingga diharapkan dapat menjawab permasalahan penelitian (Nursalam, 2008). Kriteria inklusi partisipan adalah seluruh mahasiswa profesi ners yang terdaftar aktif berkuliah di tahun ajaran 2019/2020, sedangkan, kriteria eksklusinya adalah yang tidak bersedia berpartisipasi. Jumlah partisipan dihitung menggunakan rumus slovin sehingga dari total 137 mahasiswa, minimum partisipan adalah 102 .

Pengumpulan data menggunakan kuesioner online sehingga partisipan menjawab dan mengirim secara online. Kuesioner yang digunakan untuk musik menggunakan STOMP yang dikembangkan oleh Rentfrow dan Gosling (2003) yang sudah teruji reliabilitas dan validitasnya. Ada 23 jenis musik yang ada pada STOMP ini dan skoringnya adalah dengan mengelompokkan jawaban tipe musik sesuai dengan genre musik yang disukai dengan mengambil rataratanya, dan dilanjutkan dengan menentukan preferensi musik sesuai dengan angka yang tertinggi sesuai genre yang tertinggi nilainya. Semakin tinggi nilai, semakin tinggi preferensi terhadap genre musik tersebut yang merujuk pada tipe kepribadian penyukanya. Tabel 1 merangkum genre dan tipe musik yang digunakan dalam penelitian ini.

\section{Tabel 1. Daftar Preferensi Musik}

\begin{tabular}{ll}
\hline \multicolumn{1}{c}{ Genre } & \multicolumn{1}{c}{ Tipe Musik } \\
\hline Mellow & Electric, new age, world \\
Unpretentious & Religious, country, opera \\
Sophisticated & Folk, bluegrass, blues, jazz, \\
& opera, classical, gospel \\
Heavy metal, rock, punk, & alternative \\
Contemporary & Rap, soul, funk, reggae \\
\hline
\end{tabular}

Untuk mengukur kecerdasan emosi, dipakai kuesioner yang sudah terbukti reliable dengan angka cronbach alpha $=.954$ pada penelitian sebelumnya di UIN Malang. Kuesioner ini menggunakan 40 pertanyaan dengan interpretasi skor yang didapat setelah pengambilan data dan mendapatkan hasil minimum (Min) serta maksimum (Max) dan standar deviasi (SD) yaitu yang dideskripsikan tabel 2:

\section{Tabel 2. Skoring Kecerdasan Emosi}

\begin{tabular}{|c|c|c|}
\hline Skor & Rumus & Angka \\
\hline Rendah & $x \leq([\operatorname{Min}+\operatorname{Max}] / 2)-\mathrm{SD}$ & $40-107$ \\
\hline Sedang & $\begin{array}{l}([\operatorname{Min}+\operatorname{Max}] / 2)-\mathrm{SD} \geq x \leq \\
([\operatorname{Min}+\operatorname{Max}] / 2)+\mathrm{SD}\end{array}$ & $108-130$ \\
\hline
\end{tabular}


Tinggi $\quad x \geq([\operatorname{Min}+\operatorname{Max}] / 2)+\mathrm{SD}$ $131-160$

Sumber: Azwar (1999) dalam Prakoso (2007)

Frekuensi, persentase, mean, dan standar deviasi digunakan untuk menggambarkan preferensi musik dan kecerdasan emosi. Uji Kruskal-Wallis untuk menentukan perbedaan kecerdasan emosi berdasarkan preferensi musik, dan kemudian, penilaian korelasi setiap jenis preferensi musik terhadap kecerdasan emosi, uji Spearman digunakan.

\section{Hasil}

Berdasarkan hasil penelitian selama lima hari berturutturut tanggal 6-10 November 2019 yang dirangkumkan pada tabel 3 didapati hasil rata-rata mahasiswa profesi ners menyukai tipe unpretentious dimana ada 30 orang yang menyukai musik pop, country dan religious. Sementara yang paling sedikit disukai adalah jenis musik dance, world dan new age dimana musik tersebut masuk pada genre sophisticated yang hanya dipilih 6 orang. Untuk tipe ke-6 yaitu mixed totalnya adalah 12 orang, dengan 8 orang yang merupakan gabungan Mellow dan Unpretentious, 2 orang gabungan Mellow dan Contemporary, dan 2 orang menyukai gabungan Intense dan Contemporary.

\section{Tabel 3. Preferensi Musik}

\begin{tabular}{lcc}
\hline \multicolumn{1}{c}{ Genre } & Frekuensi & Persentase \\
\hline Mellow & 22 & 21.6 \\
Unpretentious & 30 & 29.4 \\
Sophisticated & 6 & 5.9 \\
Intense & 21 & 20.6 \\
Contemporary & 11 & 10.8 \\
Mixed & 12 & 11.8 \\
$\quad$ Total & $\mathbf{1 0 2}$ & $\mathbf{1 0 0 . 0}$ \\
\hline
\end{tabular}

Tabel 4 mendeskripsikan gambaran mahasiswa profesi ners berdasarkan penelitian rata-rata memiliki tingkat kecerdasan emosional rentang sedang $(M=121.85$, $S D=11.3$ ) dan secara numerik ada 67 orang dari 102 mahasiswa yang tergolong pada rentang sedang ini.

Tabel 4. Kecerdasan Emosional

\begin{tabular}{lccc}
\hline & $\mathbf{M} \pm$ SD & $\mathrm{n}$ & $\%$ \\
\hline Kecerdasan & $121.85 \pm \mathbf{1 1 . 3}$ & & \\
Emosi & & & \\
Rendah & & 9 & 8.8 \\
Sedang & & 67 & 65.7 \\
Tinggi & & 26 & 25.5 \\
Total & & $\mathbf{1 0 2}$ & $\mathbf{1 0 0 . 0}$ \\
\hline
\end{tabular}

Berdasarkan hasil penelitian menggunakan uji non parametric Kruskal Wallis, didapati hasil tidak ada perbedaan kecerdasan emosi yang signifikan secara statistik berdasarkan preferensi musik, diindikasikan oleh nilai $p=.695(>.05)$ dan chi-square hitung $=3.035$ ( $<$ chi square tabel $=3.841$ untuk $\alpha=.05$ ).

Selanjutnya, hasil Spearman correlation pada tabel 5 menunjukkan bahwa genre musik sophisticated yang terdiri dari jenis musik folk, bluegrass, blues, jazz, opera, classical, dan gospel menunjukkan hubungan yang signifikan secara statistik dengan kecerdasan emosi dengan nilai $p=.028(<.05)$ dan nilai $r=.218$, menunjukkan korelasi positif dan lemah.

\section{Tabel 5 Korelasi Genre Preferensi Musik} dengan Kecerdasan Emosi

\begin{tabular}{lcc}
\hline \multicolumn{1}{c}{ Musik } & Koefisien Korelasi & $p$-value \\
\hline Mellow & -.050 & .615 \\
Unpretentious & .095 & .341 \\
Sophisticated & $.218^{*}$ & .028 \\
Intense & -.057 & .567 \\
Contemporary & .028 & .779 \\
\hline
\end{tabular}

Lebih spesifik lagi, terlihat bahwa uji Spearman correlation pada tabel 6 menunjukkan beberapa jenis musik seperti Gospel, New Age, Pop, Religious dan Soundtracks memiliki hubungan positif dengan kecerdasan emosi, sedangkan musik Punk memiliki hubungan yang negatif, walaupun keeratan hubungannya rendah. 
Tabel 6. Korelasi Jenis Preferensi Musik dengan Kecerdasan Emosi

\begin{tabular}{lcc}
\hline \multicolumn{1}{c}{ Musik } & Koefisien Korelasi & $p$-value \\
\hline Alternative & .044 & .659 \\
Bluegrass & -.009 & .927 \\
Blues & .113 & .259 \\
Classical & .102 & .307 \\
Country & .079 & .433 \\
Dance & .005 & .958 \\
Folk & .095 & .342 \\
Funk & -.104 & .297 \\
Gospel & $.310^{* *}$ & .002 \\
Heavy Metal & -.124 & .214 \\
World & .149 & .135 \\
Jazz & .192 & .053 \\
New Age & $.206^{*}$ & .038 \\
Oldies & .149 & .134 \\
Opera & .187 & .059 \\
Pop & $.352^{* *}$ & .000 \\
Punk & $-.196^{*}$ & .048 \\
Rap & .105 & .292 \\
Reggae & .066 & .509 \\
Religious & $.317 * *$ & .001 \\
Rock & -.157 & .115 \\
RnB & .172 & .084 \\
Soundtracks & $.236^{*}$ & .017 \\
\hline${ }^{*}$ p .05; **p $<.01$ & &
\end{tabular}

\section{Pembahasan}

West (2009) berpendapat bahwa "suara memiliki kemampuan untuk memotong sistem kesadaran linguistik dan merangsang emosi dengan cara yang kurang kita sadari secara verbal.” Hubungan antara kecerdasan emosional dan suara khususnya musik memiliki hubungan erat dengan kecerdasan emosional, dimana berdasarkan STOMP mahasiswa profesi ners memiliki kepribadian unpretentious yang berarti cenderung memiliki sifat konservatif, kurang terbuka dan tidak tertarik untuk mengeksplorasi perasaan.

Preferensi musik unpretentious sendiri, memiliki tingkat kecerdasaan emosional dengan tingkatan sedang atau seimbang, hal ini diungkapkan oleh Mellander, et al (2018) disebutkan bahwa preferensi musik bertipe unpretentious dari segi tipe kepribadian, mereka cenderung lebih menyenangkan dan teliti. Walaupun begitu tidak bisa diabaikan bahwa mahasiswa profesi ners juga memiliki preferensi Mellow dan Intense serta ditemukan juga mahasiswa yang memiliki kualitas kecerdasan emosional pada tingkatan tinggi. Sehingga preferensi musik sendiri bukanlah satu-satunya faktor penentu tingkat kecerdasaan emosional itu sendiri, melainkan bagaimana peserta yang memiliki kecerdasan emosional lebih tinggi menggunakan dan mendengarkan musik dengan cara yang berbeda dari rekan-rekan mahasiswa profesi ners lainnya, walaupun mereka tidak sadar akan hal tersebut.

Tidak terdapat perbedaan kecerdasan emosi yang signifikan secara statistik berdasarkan preferensi musik mahasiswa profesi ners, namun ada hubungan yang signifikan secara statistik antara preferensi musik genre "sophisticated" dan jenis Gospel, New Age, Pop, Punk, Religious dan Soundtracks dengan kecerdasan emosional. Genre "sophisticated" terdiri dari musikmusik dengan jenis folk, bluegrass, blues, jazz, opera, classical, dan gospel yang lebih tenang mengalun. Gospel, New Age, Pop, Religious dan Soundtracks memiliki hubungan positif dengan kecerdasan emosi, sedangkan musik Punk memiliki hubungan yang negatif. Dari jenis-jenis musik ini, Gospel, New Age, Pop, Religious dan Soundtracks memiliki melodi, harmoni dan irama yang cenderung mengalun dengan tenang dan tidak cenderung cepat, dibandingkan dengan musik Punk yang cenderung keras dan cepat.

Secara teori, Schaefer (2017) mengutip bahwa ada empat parameter musik untuk aktivasi emosi yaitu tempo, harmoni (consonance yang merupakan antonim dari dissonance), warna nada (timbre) dan keraslembutnya musik tersebut. Secara spesifik, tempo musik mempengaruhi dinamika kardiovaskular, sedangkan kategori harmoni (consonance) dapat diasosiasikan dengan area paralimbik dan korteks dalam otak dimana musik dissonance akan memunculkan sensasi kekasaran karena memodulasikan aktivitas amigdala. Kerasnya musik atau tekanan suara fisik tampaknya berhubungan dengan respon psikoneuroendokrin.

Hubungan antara musik dan emosi sudah diterima sepanjang masa (Trimble \& Hesdorffer, 2017) dan hanya mendengar musik, maka pusat dan area otak yang mengatur penghargaan akan diaktifkan dan mengakibatkan pengalaman emosional yang dalam (Gleason, 2014) serta mempengaruhi alam perasaan (Schafèr, et al., 2013). Sugawa dan Yonetani dalam University of Central Florida (n.d.) menjelaskan secara detail bahwa musik mempengaruhi berbagai region otak yaitu nucleus accumbens, amygdala dan hippocampus yang berhubungan erat juga dengan emosi. Lebih lanjut, teori sebelumnya yang ditulis oleh Aristotle (1984) bahwa "... emosi apa pun diproduksi dari melodi dan ritme; karena itu dengan musik manusia menjadi terbiasa merasakan emosi yang tepat. Musik memiliki kekuatan untuk membentuk karakter dan beragama (beriman). Jenis musik berdasarkan berbagai kategori, mungkin dibedakan oleh efeknya berdasarkan karakter dari suatu musik." 
Hasil penelitian ini didukung dengan penelitian sebelumnya oleh Lonsdale (2018) menemukan bahwa ada hubungan antara kecerdasan emosi dan musik walaupun tidak langsung. Hal yang sama ditemukan oleh Năstasă dan Ionescu (2015) yang menemukan musik favorit berhubungan dengan kecerdasan emosi. Di area lokal dan lebih spesifik, Elfira (2015) di Institut Seni Indonesia, Yogyakarta menemukan bahwa musik memiliki pengaruh terhadap kecerdasan emosional seseorang, khususnya klasik dan pop-jazz.

\section{Kesimpulan}

Berdasarkan hasil penelitian didapati kesimpulan bahwa mahasiswa Profesi Ners paling banyak menyukai musik bertema unpretentious yaitu: pop, country dan religious. Lebih lanjut, rata-rata mahasiswa juga memiliki kecerdasan emosional kategori sedang. Berikutnya, uji non parametric Kruskal-Wallis menemukan tidak terdapat perbedaan kecerdasan emosi yang signifikan secara statistik berdasarkan preferensi musik mahasiswa profesi ners, sedangkan uji Spearman menunjukkan ada hubungan yang signifikan secara statistik antara preferensi musik. Secara spesifik, genre musik "sohisticated" dan jenis musik Gospel, New Age,

\section{Daftar Pustaka}

Aristotle. (1984). The politics. Translated and with an introduction, notes and glossary by Carnes Lord. Chicago: The University of Chicago Press.

Elfira, S. (2015). Hubungan Karakter Musik Klasik dan Pop-Jazz dengan Kecerdasan Emosi (Eq) Mahasiswa Jurusan Musik Institut Seni Indonesia Yogyakarta. Diakses di http://digilib.isi.ac.id/610/1/BAB\%201.pdf

Fitroh, S. F., \& Khasanah, S. M. (2016). Musik Sebagai Stimulus Pada Kecerdasan Emosi Anak. Jurnal PG- PAUD Trunojoyo diakses pada tanggal 12 September 2019.

Gleason, M. E. (2014). Musical aptitude and emotional intelligence. Diakses dari: https://dspace.sunyconnect.suny.edu/handle/19 $51 / 65092$

Goleman, D. (2000). Kecerdasan Emosional; Mengapa EI Lebih Penting daripada IQ. Jakarta: PT. Gramedia Pustaka Utama.
Pop, Religious dan Soundtracks memiliki hubungan positif dengan kecerdasan emosi, sedangkan Punk memiliki hubungan yang negatif, walaupun keeratan hubungannya masing-masing adalah rendah. Hasil penelitian ini dapat menjadi bahan acuan untuk mengetahui kepribadian seseorang serta media penentu untuk meningkatkan kecerdasan emosional berdasarkan jenis musik yang disukai.

Bagi mahasiswa profesi ners kiranya dapat bijaksana memilih jenis aliran musik tertentu guna meningkatkan kecerdasan emosional. Bagi peneliti selanjutnya yang ingin mengadopsi dan menggunakan Tes Preferensi Musik (STOMP) dalam penelitian di masa depan harus memastikan bahwa mereka mendengarkan setidaknya satu dari lagu-lagu tersebut, agar peserta dapat memahami jenis musik yang dimaksud. Selain itu, untuk kecerdasan emosi, kuesioner yang digunakan dipenelitian ini adalah "self-rated" sehingga partisipan bisa menjawabnya dengan "harapan" terhadap diri dan bukan "fakta". Hal ini dapat dihindari dengan pengukuran observasi perilaku langsung dengan memberikan ujian situasional kepada partisipan.

Hamzah, B. (2010). Orientasi Baru dalam Psikologi Pembelajaran. Jakarta : Bumi Aksara

Iqlima, I. R. (2019). Pengaruh murottal al-Qur'an terhadap kecerdasan emosional anak kelompok A di TK Islam an-Nur Bungur Karangrejo Tulungagung. Diakses di http://repo.iaintulungagung.ac.id/12508/4/BAB\%20I.pdf pada tanggal 28 November 2019.

Kompasiana. (2018). Musik untuk Kecerdasan Emosi Anak. Diakses di https://www.kompasiana.com/baldwine_hon est/5be18a03bde575429860a3b2/musikuntuk-kecerdasan-emosi-anak

Lonsdale, A.J. (2018). Emotional intelligence, alexithymia, stress, and people's reason for listening to music. Diakses di:https://journals.sagepub.com/doi/abs/10.117 7/0305735618778126

Mellander, C. et al. (2018). Title of journal article The geography of music preferences P. $16-20$ 
Năstasă, L.-E., \& Ionescu, E. (2015). Favorite Musical Styles, Emotional Intelligence and Adolescent' Personality. Procedia - Social and Behavioral Sciences, 187, 83-87. doi: 10.1016/j.sbspro.2015.03.016

Nursalam. (2008). Konsep dan Penerapan Metodologi Penelitian Ilmu Keperawatan : Pedoman Skripsi, Tesis, dan Instrumen..Edisi 2. Jakarta : Salemba Medika.

Prakoso, D. W. F. (2007). Deskripsi tingkat kecerdasan emosional perawat rumah sakit Santa Elisabeth Purwokerto. Skripsi. Diakses dari: https://repository.usd.ac.id/29964/2/99911403 3_Full\%5B1\%5D.pdf

Rentfrow, P. J., \& Gosling, S. D. (2003). The do re mi's of everyday life: The structure and personality correlates of music preferences. Journal of Personality and Social Psychology, 84, 12361256. Diakses dari: https://gosling.psy.utexas.edu/scales-wevedeveloped/short-test-of-music-preferencesstomp/

Sandi, F. (2018). Pengaruh Musik terhadap Kecerdasan Emosional. Jurnal Ilmu pendidikan diakses pada tanggal 10 September 2019.
Schäfer, T., Sedlmeier, P., Städtler, C., \& Huron, D. (2013). The psychological functions of music listening. Front Psychol. 2013; 4: 511. doi: 10.3389/fpsyg.2013.00511. Diakses dari: https://www.ncbi.nlm.nih.gov/pmc/articles/PM C3741536/

Schaefer, H.-E. (2017). Music-Evoked EmotionsCurrent Studies. Frontiers in

Neuroscience, 11. doi: 10.3389/fnins.2017.00600. Diakses dari: https://www.ncbi.nlm.nih.gov/pmc/articles/PM C5705548/

Trimble, M. \& Hesdorffer, D. (2017). Music and the brain: the neuroscience of music and musical appreciation. BJPsych Int. 2017 May; 14(2): 28-31. Diakses dari: https://www.ncbi.nlm.nih.gov/pmc/articles/PM C5618809/

University of Central Florida (n.d.). Your brain on music. Diakses dari: https://www.ucf.ed/pegasus/your-brain-onmusic/

West, T. (2009). Music and designed sound. In C. Jewitt (2009). The routledge handbook of multimodal analysis. London: Taylor and Francis. P. 284 - 292. 